\title{
Use of a Tailored, Multifaceted Educational Approach for Prevention and Early Detection of Delirium in Hospitalized Elderly Patients
}

Rong Fang Zhang., MN, BHSN, Advanced Dip (Gerontology), RN ${ }^{1,2}$; Si Ching Lim. MB, ChB, MBBS (UK) , MRCP (UK) ${ }^{3}$; Siok Bee Tan, PhD, RN ${ }^{1,4}$; Vignesh Sivasamy, BSc, MBBS, MRCP(UK) Wee Ching Foo, BSN, RN ${ }^{1,5}$; Julian Hui Min Lee, MN, BSN, RN ${ }^{1,5}$; King Fan Yip, MBBS, AST, MRCP (UK) ${ }^{5}$; Eleanor S. McConnell, PhD, RN ${ }^{6,7,8}$.

${ }^{1}$ Nursing Division, Speciality Nursing, Singapore General Hospital, Singapore.

${ }^{2}$ Department of Rheumatology \& Immunology, Singapore General Hospital, Singapore.

${ }^{3}$ Department of Geriatric Medicine, Changi General Hospital, Singapore.

${ }^{4}$ Department of Neurology Medicine, Singapore General Hospital, Singapore.

${ }^{5}$ Department of Geriatric Medicine, Singapore General Hospital, Singapore.

${ }^{6}$ Duke University School of Nursing, Durham, NC, USA.

${ }^{7}$ Geriatric Research, Education and Clinical Center, Durham Veterans Affairs Health Care System, Durham, NC, USA.

${ }^{8}$ Duke University Center for the Study of Aging and Human Development, Durham, NC, USA.

*Corresponding Author: Si Ching Lim, Department of Geriatric Medicine, Changi General Hospital, Singapore.

Abstract

Aim: The aim of this scholarly project was to implement and evaluate the efficacy of a tailored, multifaceted nursing educational program in prevention, early detection leading to early management of delirium in older adults aged 65 and above.

Background: Delirium is a medical emergency which compromises patient safety due to its many negative consequences such as falls, prolonged hospitalisation, and increased use of restraints. Delirium is often missed or diagnosed late by physicians. As the frontline in patient care, nurses play an important role in early delirium detection and prevention. Therefore, educating nurses on delirium prevention and clinical application of a delirium screening tool is deemed necessary in caring for the elderly patients aged $>65$.

Design: This was a three-phase study employing two-independent group pre-post design conducted at two mixed acute general medical/surgical wards in a large tertiary hospital.

Methods: Phase 0 was to establish nurses' baseline knowledge of delirium, incidence of delirium, falls, restraint use, and length of stay amongst the eligible patients. Phase I was to implement the educational program which comprised of theoretical and practical components to the registered nurses in the two wards. Trained nurses then applied modified 4AT and delirium care bundle to eligible patients in Phase II.

Results: Total of 61 nurses were involved in the training. There was significant improvement in nurses' knowledge of delirium after training, which was sustained at one month later. A total of 100 patients were recruited. The incidence of delirium was $8 \%$ in phase 0 and $6 \%$ in phase II. Patients with delirium had longer length of stay than patients without delirium. There was no significant difference in falls, restraint use and length of stay.

Conclusions: A multifaceted delirium educational program improved nurses' knowledge in delirium screening and prevention. A longer study period for larger enrolment of patients is recommended to evaluate the longer term retention of knowledge and the effects on patient care.

Keywords: Delirium, delirium screening, delirium prevention, 4AT, delirium bundle, delirium education 
Use of a Tailored, Multifaceted Educational Approach for Prevention and Early Detection of Delirium in Hospitalized Elderly Patients

\section{What does this paper contribute to the wider global clinical community?}

- Delirium education, with combination of theoretical and practical components improve nurses' knowledge in delirium.

- $4 \mathrm{AT}$, a delirium screening tool, can be adopted for hospital wide use in clinical practice to screen for delirium.

- Delirium care bundle consists a set of non-pharmacological interventions, is of benefit to the patients, and helped the nurses in terms of ease of documentation.

\section{INTRODUCTION}

Delirium is a medical emergency, characterised by an acute onset, altered mental status and altered behavioural symptoms. The elderly patients, especially the ones with background dementia, are more vulnerable to develop delirium. Singapore is facing a rapidly aging population which is estimated to reach from $15.2 \%$ in 2020 to $32 \%$ by 2035 [1]. About one third of the total hospital admissions are occupied by elderly aged 65 and above with multiple comorbidities, functional decline, and social issues ${ }^{[2]}$. These vulnerable elderly are at higher risk of developing delirium. Delirium is associated with poor clinical outcomes, such as increased risk of fall and restraint use ${ }^{[3,4]}$, increased long term mortality ${ }^{[5,6]}$, and prolonged hospitalisation ${ }^{[7]}$. The incidence of delirium is high and varies across the various disciplines in the acute hospital settings. For example, incidence of delirium estimates range from $4 \%$ to $53 \%$ among patients with hip fracture, ${ }^{[8]}, 21.4 \%$ in cardiac surgery unit ${ }^{[9]}, 20 \%$ post esophagectomy ${ }^{[10]}$, and $31.3 \%$ to $40.4 \%$ in general medical setting ${ }^{[11,12]}$. Healthcare professionals often under recognize delirium in its early course, due to the fluctuating nature of the disease, especially for hypoactive and sub-syndromal types. Delirium is missed among 30\% of emergency department (ED) physicians and up to $60 \%$ of physicians ${ }^{[13]}$. Underdiagnosis of delirium is a great concern with about $70 \%$ of patients being overlooked ${ }^{[11]}$.

Early detection and prevention of delirium are strongly recommended by various delirium clinical guidelines such as National Institute for Health and Care Excellence (NICE) for delirium prevention, diagnosis, and management [14]; American Geriatrics Society guideline for postoperative delirium ${ }^{[15]}$, and Registered Nurses Association of Ontario for delirium screening, assessment and care ${ }^{[16,17]}$. These guidelines strongly recommend education as an integral part of a multicomponent non-pharmacological intervention for delirium prevention and detection. Systematic reviews also revealed positive outcomes in delirium early detection and prevention with education as the one of the core components ${ }^{[18,19]}$.

Various studies looking at the effect of multicomponent non-pharmacological interventions have in certain degree reduced the incidence of delirium, improved fall prevention, and decreased length of stay (LOS) [20-22]. Multiple systematic review, and meta-analysis $[18,25,26]$, and evidence based quality improvement projects evaluated with before and after design, demonstrated that multicomponent non-pharmacological interventions, especially the Hospital Elderly Life Program (HELP) that included an education component for nurses, showed favourable results in reducing incidence of delirium and its negative consequences ${ }^{[23-25]}$.

With the high incidence and under-recognition of delirium by physicians, coupled with the benefits of nurses' contribution in screening for and prevention of delirium, nurses should be trained by leveraging on an effective delirium screening tool and nonpharmacological measures to reduce new onset of delirium during hospital stay and its complications. The available evidence which supports delirium education for nurses included both theoretical and practical components ${ }^{[20-24,27]}$. Theoretical components consist of definition of delirium, clinical features, risk factors and causes, a delirium screening/assessment tool, and non-pharmacological measures for delirium prevention. The practical components include correct application of a delirium screening/assessment tool and implementation of non-pharmacological measures. 4AT delirium screening tool was chosen as it requires minimal training, is easy to use, time saving, and with sensitivity and specificity of more than $80 \%$ 
Use of a Tailored, Multifaceted Educational Approach for Prevention and Early Detection of Delirium in Hospitalized Elderly Patients

in the detection of delirium ${ }^{[28-31]}$. A Singapore version of modified 4AT delirium screening tool was used as it had achieved sensitivity $100 \%$ and specificity $93.6 \%$ (Li, Lim, \& Png, 2020. unpublished result).

The aim of this scholarly project was to explore the effect of a tailored, multifaceted educational approach for nurses on improving their knowledge of delirium and application of the modified 4AT delirium screening tool and a bundle of non-pharmacological measures in older adults. The effects on patients' incidence of delirium, falls, restraint use, and LOS were included as secondary outcomes.

\section{METHODS}

\section{Project Design, Setting and Participants}

This was a three-phase project employing a twoindependent group pre-post design conducted at two mixed medical/surgical wards at the largest tertiary hospital in Singapore from $15^{\text {th }}$ July 2020 to $13^{\text {th }}$ Oct 2020. The total bed capacity was 72,42 in ward A and 30 in ward B. The weekly average percentage of patients aged $>65$ in ward $\mathrm{A}$ and $\mathrm{B}$ were $88.1 \%$ and $73.3 \%$ respectively. The weekly turnover rate was

Table1. Modified 4AT Delirium Screening Tool
$10.8 \%$ in ward $\mathrm{A}$ and $13.6 \%$ in ward $\mathrm{B}$. Patients aged $>65$, newly admitted to the two wards under the department of Internal Medicine (IM) and General Surgery (GS) were all included in the project during the study period. There were no exclusion criteria. All registered nurses in the two wards were included for the training. The project was approved by Centralised Institutional Review Board (CIRB) of the institution. Written consent was obtained from patients or their next of kin.

\section{Instruments}

\section{Modified 4AT Delirium Screening Tool}

The modified 4AT comprises four items as listed in the table 1 . Item 3 was modified to test attention by counting numbers backwards from 20 to1, instead of reciting the months of the year backwards. Reciting the months of the year backwards in the local culture would be counting from 12 to 1 . Counting backwards from 20 to 1 has been validated in the local abbreviated mental test (AMT). To assist patient's understanding, nurses prompted patient once by subtracting 1 from 20.

\begin{tabular}{|l|l|}
\hline Items & Explanation \\
\hline 1. Alertness & An observational assessment of level of alertness \\
\hline 2. AMT4 & $\begin{array}{l}\text { 4 items extracted from the Abbreviated Mental Test (AMT), which asks the patient to } \\
\text { state their age, date of birth, the current year, and the place they are in. }\end{array}$ \\
\hline 3. Attention & Tests attention by counting numbers backwards from 20 to 1. \\
\hline $\begin{array}{l}\text { 4. Acute change or } \\
\text { fluctuating course }\end{array}$ & $\begin{array}{l}\text { Measures the acute change in mental status, which is the core diagnostic feature of de- } \\
\text { lirium. Information to assess this change can be obtained from the medical records, or } \\
\text { any referral letter, or from caregivers/family members. }\end{array}$ \\
\hline
\end{tabular}

Items 1-3 are done at the bedside, which takes about 2 minutes.

\section{Case Vignettes of Hospitalized Older Adults (CVHOA)}

Five case vignettes, which were developed and evaluated by a panel of geriatric and psychiatric experts, were used to assess healthcare providers' knowledge on different subtypes of delirium (Fick, Hodo, Lawrence, and Inouye, 2007). The reported overall agreement on the cases and the identification of delirium subtypes were $84 \%$ and $100 \%$ respectively (Fick et. al, 2007). Using case vignettes provided standardised assessment of nurses' knowledge of delirium.

\section{Intervention \& Procedure}

A delirium workgroup (DWG) was formed consisting of a Doctor of Nursing Practice (DNP) student as project lead, two geriatricians, three geriatric speciality nurses, one general surgeon, and two of the ward nurses were identified as the delirium champions.

In Phase 0, patients' baseline data were collected by the second day upon their admission or transferring to the two wards. Only patients admitted under the department of Internal Medicine (IM) and General Surgery (GS) were included in this project. Written 
Use of a Tailored, Multifaceted Educational Approach for Prevention and Early Detection of Delirium in Hospitalized Elderly Patients

consent was obtained from patients or their next of kin before data collection and examination of patient's mental status by checking their orientation to time, person and place (TPP). DWG members assessed TPP on each patient twice daily until their discharge. Modified 4AT was performed twice daily if patients failed to identify any one of the TPP correctly. If modified 4AT score was $>4$, nurse in-charge was notified to inform the primary team doctors. Appropriate investigations and management were then initiated by the primary team doctors using the Computerised Physician Order Entry (CPOE) system. Nurses carried out the primary team doctors' orders as documented in CPOE and Clindoc (a secured online documentation) an routine nursing care. Diagnosis of delirium, falls, restraint use, and LOS were collected. Nurses' demographic data were collected at last week of Phase 0 and nurses' knowledge of delirium were evaluated using CVHOA at the same period.

Phase Iinvolved the implementation of the multifaceted educational program amongst nursing staff. DNP student, geriatric nurses and ward champions conducted the educational training which consisted of both theoretical and practical components. Theoretical components consisted of delirium definition, clinical features, predisposing and precipitating factors, comparison between delirium and dementia, common underlying causes, non-pharmacological measures grouped as "delirium care bundle (DCB)", case vignettes to differentiate dementia and subtypes of delirium, and the modified 4AT delirium screening tool. Theoretical knowledge was conducted through a series of one hour long in-service session to cover all the ward nurses. The practical components included appropriate application of the modified $4 \mathrm{AT}$ and implementation of DCB. DCB consisted of reality orientation, sensory stimulation, maintain hydration and nutrition, ensure elimination, early mobilization, promote comfort, sleep hygiene, and avoidance of restrain use. Nurses' knowledge of delirium was measured using CVHOA one week after each training session over a total of two weeks.

Phase II examined how well the nurses in the two wards applied their knowledge in the clinical setting. They were tasked to assess all eligible patients admitted under IM and GS for their mental state, by checking patients' orientation to TPP once per shift three times per day as the signs and symptoms of delirium typically fluctuate. If patient was unable to identify any one of the TPP correctly, nurses proceeded to screen patient with the modified 4AT and initiate DCB. If the score was $>4$, nurses would notify the primary team doctors. Primary team doctors followed the standard practice as in Phase 0 . Nurses also carried out the primary team doctors' orders as documented in CPOE and Clindoc. The incidence of delirium, falls, restraint use, and LOS were documented. All patients were assessed daily until their discharge or transfer. Nurses' knowledge of delirium at 1-month post training were measured using CVHOA before the end of the project. Ongoing support by DWG members was provided to nurses on weekly interval and ad hoc basis if there were any queries. Feedback from nurses was gathered during Phase I and Phase II.

\section{Measurements}

\section{Baseline Data}

Patients' data collected included age, gender, race, educational level, current smoking and alcohol history, number of chronic medical conditions, accommodation and ambulatory status, number of delirium risk factors, history of falls, falls during hospitalization, restraint use, and LOS. Nurses' demographic data included age, gender, race, educational level, years of experience, prior education in delirium, prior experience in nursing patients with delirium, awareness of delirium screening tool, and awareness of the availability of delirium education materials.

\section{Primary Outcomes}

The primary outcomes of this study were to examine nurses' knowledge of delirium, TPP screening rate, 4AT screening rate, and uptake of DCB. Nurses' knowledge of delirium was measured by the total number of correct answers identified in CVHOA. TPP screening rate was calculated as the total number of TPP checked by nurses on each eligible patient divided by the ideal total number of TPP checked on each patient within the patient's hospitalization in the study ward. The ideal total number of TPP was calculated using the days of hospitalization times three as TPP was checked at three times per day. The 4AT screening rate was calculated as the total number of $4 \mathrm{AT}$ checked by nurses on each eligible patient divided by the ideal total number of $4 \mathrm{AT}$ performed on each eligible patient. The ideal total number of 
Use of a Tailored, Multifaceted Educational Approach for Prevention and Early Detection of Delirium in Hospitalized Elderly Patients

4AT was calculated using three times the number of days of which patient failed to answer any one of the TPP correctly within the patient's hospitalization in the study ward. 4AT was not routinely checked on all patients, unless there was a change of mental status. The uptake of DCB was calculated as the number of DCB each eligible patient received divided by the ideal total number of DCB each eligible was supposed to receive. The ideal total number of DCB was calculated the same way as the ideal number of ideal 4 AT being calculated.

\section{Secondary Outcomes}

The secondary outcome measures were incidence of delirium, falls rates, restraint use, and LOS. Incidence of delirium was defined as the total number of new delirium cases detected during hospitalisation within the project period. Falls rates was defined as number of falls per 1,000 person-years occupied. Length of stay was defined as the number of days in the hospital from the date of admission to the the date of discharge or transferring out from the two wards.

\section{Analysis}

Statistical Package for the Social Sciences (SPSS) version 25 (SPSS Inc., Chicago, IL) was used to perform the data analysis. For quantitative data, descriptive statistics were analysed, including mean, standard deviation, number and percentage. Independent $\mathrm{t}$ test was used to compare the difference for numerical data. Chi square test was used for compare categorical data. TPP screening rate was analysed using $X^{2}$ test to compare patients with delirium vs no delirium received TPP screening with a cut-off point $80 \%$ in Phase II. For those patients who need to be screened using modified 4AT, 4AT screening rate and delirium update rate were compared using a cut-off point of $80 \%$. Repeated measure ANOVA was used to compare nurses' knowledge of delirium in Phase 0, Phase I, and Phase II. P value of 0.05 or lesser was considered significant.

\section{RESULTS}

\section{Study Participants}

\section{Patients}

There was a total of 189 eligible patients admitted to the two wards in Phase 0 and Phase II. Total of 100 patients consented to the project with 50 each in both Phase 0 and Phase II. The recruitment percentage was similar in the two wards with $67.74 \%$ at ward A and $61.70 \%$ at ward B in Phase 0 , and $45.21 \%$ at ward A and $45.95 \%$ at ward B in Phase II (Table 2.). There was no significant difference in baseline characteristics of patients in Phase 0 and Phase II except number of comorbidities which were higher in Phase 0 with $(\mathrm{M}=9.4, \mathrm{SD}=3.46)$ than Phase II $(\mathrm{M}=7.84, \mathrm{SD}=3.38)$; $\mathrm{t}(98)=2.28, \mathrm{p}=0.03$ (Table 3.).

Table2. Recruitment Percentage \& Reasons for Decline

\begin{tabular}{|c|c|c|c|c|c|c|}
\hline \multirow[b]{2}{*}{ Wards } & \multicolumn{3}{|c|}{ Phase 0} & \multicolumn{3}{|c|}{ Phase II } \\
\hline & Ward A & Ward B & Total & Ward A & Ward B & Post Total \\
\hline Recruited & 21 & 29 & 50 & 33 & 17 & 50 \\
\hline Declined & 10 & 19 & 29 & 40 & 20 & 60 \\
\hline Total Admission (IM/GS*) & 31 & 48 & 79 & 73 & 37 & 110 \\
\hline Recruit percentage & $67.74 \%$ & $61.70 \%$ & $63.29 \%$ & $45.21 \%$ & $45.95 \%$ & $45.45 \%$ \\
\hline \multirow[t]{5}{*}{ Reasons for decline } & \multicolumn{3}{|c|}{ Declined by patient - 6} & \multicolumn{3}{|c|}{ Declined by patient - 7} \\
\hline & \multicolumn{3}{|c|}{ Declined by family member - 14} & \multicolumn{3}{|c|}{ Declined by family member- 23} \\
\hline & \multicolumn{3}{|c|}{$\begin{array}{l}\text { Missed opportunity to ask for consent } \\
\text { due to the working arrangement - } 5\end{array}$} & \multirow{2}{*}{\multicolumn{3}{|c|}{$\begin{array}{l}\text { Unable to meet Family member to obtain } \\
\text { consent due to working arrangement - } 9 \\
\text { Readmission - } 1\end{array}$}} \\
\hline & \multicolumn{3}{|c|}{ Missed due to short LOS - 3} & & & \\
\hline & \multicolumn{3}{|c|}{$\begin{array}{l}\text { Care taken over and transferred out } \\
\text { to another Discipline }-1\end{array}$} & & & \\
\hline
\end{tabular}

*IM = Internal Medicine; GS = General Surgery 
Use of a Tailored, Multifaceted Educational Approach for Prevention and Early Detection of Delirium in Hospitalized Elderly Patients

Table3. Baseline Characteristics of Patients $(n=100)$

\begin{tabular}{|c|c|c|c|c|c|}
\hline \multicolumn{2}{|l|}{ Characteristics } & \multirow{2}{*}{$\begin{array}{c}\text { Phase 0 } \\
76.4(+7.62)\end{array}$} & \multirow{2}{*}{$\begin{array}{c}\text { Phase II } \\
77.8(+7.86)\end{array}$} & \multirow[t]{2}{*}{$\mathrm{X} 2$} & \multirow{2}{*}{$\begin{array}{c}\text { p value } \\
0.37 \\
\end{array}$} \\
\hline Age in years, Mean (+ SD) & & & & & \\
\hline \multirow{2}{*}{ Gender, n (\%) } & Male & $17(34 \%)$ & $9(18 \%)$ & \multirow[t]{2}{*}{0.002} & \multirow[t]{2}{*}{0.64} \\
\hline & Female & $33(66 \%)$ & $41(82 \%)$ & & \\
\hline \multirow[t]{3}{*}{ Race, n (\%) } & Chinese & $44(88 \%)$ & $43(86 \%)$ & \multirow[t]{3}{*}{0.95} & \multirow[t]{3}{*}{0.92} \\
\hline & Malay & $1(2 \%)$ & $5(10 \%)$ & & \\
\hline & Indian & $5(10 \%)$ & $2(4 \%)$ & & \\
\hline \multirow[t]{4}{*}{ Education, n (\%) } & No education & $12(24 \%)$ & $20(40 \%)$ & \multirow[t]{4}{*}{6.51} & \multirow[t]{4}{*}{0.69} \\
\hline & Primary & $25(50 \%)$ & $17(34 \%)$ & & \\
\hline & Secondary & $10(20 \%)$ & $10(20 \%)$ & & \\
\hline & Tertiary & $3(6 \%)$ & $3(6 \%)$ & & \\
\hline \multirow[t]{3}{*}{ Current smoke history, n (\%) } & Yes & $6(12 \%)$ & $2(4 \%)$ & \multirow[t]{3}{*}{3.72} & \multirow[t]{3}{*}{0.45} \\
\hline & No & $37(74 \%)$ & $42(84 \%)$ & & \\
\hline & Ex-smoker & $7(14 \%)$ & $6(12 \%)$ & & \\
\hline \multirow[t]{3}{*}{ Current alcohol history, n (\%) } & Yes & $3(6 \%)$ & 0 & \multirow[t]{3}{*}{0.22} & \multirow[t]{3}{*}{0.89} \\
\hline & No & $41(82 \%)$ & $49(98 \%)$ & & \\
\hline & Ex-drinker & $6(12 \%)$ & $1(2 \%)$ & & \\
\hline \multirow[t]{4}{*}{ Accommodation, n (\%) } & Alone & $6(12 \%)$ & $7(14 \%)$ & \multirow[t]{4}{*}{3.35} & \multirow[t]{4}{*}{0.50} \\
\hline & With Helper & $2(4 \%)$ & 0 & & \\
\hline & With Family & $42(84 \%)$ & $42(84 \%)$ & & \\
\hline & Nursing Home & 0 & $1(2 \%)$ & & \\
\hline \multirow[t]{5}{*}{ Ambulating Status, n (\%) } & Independent & $30(60 \%)$ & $26(52 \%)$ & \multirow[t]{5}{*}{25.00} & \multirow[t]{5}{*}{0.07} \\
\hline & Walking Frame & $4(8 \%)$ & $4(8 \%)$ & & \\
\hline & Walking Stick & $9(18 \%)$ & $16(32 \%)$ & & \\
\hline & Wheelchair & $3(6 \%)$ & $2(4 \%)$ & & \\
\hline & Bedbound & $4(8 \%)$ & $2(4 \%)$ & & \\
\hline \multirow[t]{2}{*}{ Functional status, n (\%) } & Home Bound & $14(28 \%)$ & $11(22 \%)$ & \multirow[t]{2}{*}{0.004} & \multirow[t]{2}{*}{0.64} \\
\hline & Community ambulant & $36(72 \%)$ & $39(78 \%)$ & & \\
\hline \multirow[t]{2}{*}{ Fall history, n (\%) } & Yes & $23(46 \%)$ & $22(41 \%)$ & 2.71 & 0.10 \\
\hline & No & $27(54 \%)$ & $28(59 \%)$ & & \\
\hline No. of Comorbidities, Mean $(+5$ & & $9.4(+3.46)$ & $7.84(+3.38)$ & & 0.03 \\
\hline Delirium Risk Factors, Mean (+ & SD) & $7.68(+2.40)$ & $7.56(+2.82)$ & & 0.82 \\
\hline
\end{tabular}

\section{Nurses}

There were 63 registered nurses in the two wards. 61 of them were included in the project as one nurse was on non-pay leave, and one was on long hospitalization leave. Their characteristics were summarised in table
4. There were two nurses from ward B who dropped out in Phase I. One of them was transferred out, and the other was deployed. In Phase II, five nurses dropped out (two resignations, two transfer out, and one external deployment). Therefore, a total of 54 nurses were included in the final data analysis. A total 
Use of a Tailored, Multifaceted Educational Approach for Prevention and Early Detection of Delirium in Hospitalized Elderly Patients

of 18 training sessions were conducted to train the 61 nurses. Each session only involved 5 nurses to avoid

Table4. Characteristics of Nurses $(n=61)$ over-crowding and maintain social distancing during the current COVID-19 pandemic.

\begin{tabular}{|l|l|}
\hline Characteristics & \\
\hline Working experience in years, Mean (+SD) & $7.8(+4.33)$ \\
\hline Education Level, n (\%) & \\
\hline \multicolumn{1}{|c|}{ Diploma } & $24(39.3 \%)$ \\
\hline$\quad$ Bachelor Degree & $33(54.1 \%)$ \\
\hline$\quad$ Master Degree & $2(3.3 \%)$ \\
\hline Experience in Nursing Delirium Patients, n (\%) & $2(3.3 \%)$ \\
\hline Not attended any Delirium Talk Before, n (\%) & $58(95.1 \%)$ \\
\hline Not Aware of availability of Delirium Teaching Materials in the Hospital, $\mathrm{n}(\%)$ & $37(60.7 \%)$ \\
\hline Awareness of Delirium Screening Tool, n (\%) & $59(96.7 \%)$ \\
\hline Identified at least One Delirium Screening Tool Correctly, n (\%) & $12(19.7 \%)$ \\
\hline
\end{tabular}

\section{Primary Outcomes}

\section{Nurses' Delirium Knowledge}

There was a significant positive effect of the multifaceted educational approach in improving nurses' knowledge of delirium with Wilks' Lamda $=0.49, F(2,54)=27.11$, $\mathrm{p}<0.001$. Pairwise comparison showed that there was a significant improvement in nurses' knowledge of delirium with $\mathrm{p}<0.05$ in both Phase 0 vs Phase I, and Phase 0 vs Phase II $(\mathrm{p}<0.05)$. The results were sustained at one month post training with $\mathrm{p}=0.28$ between Phase I and Phase II.

\section{TPP, 4AT and DCB}

There was no difference between patients with delirium versus no delirium in receiving TPP screening in Phase II at cut off point of $80 \%$ with $X^{2}(1)=0.45$, $\mathrm{p}=0.47 .12$ patients in Phase 0 and 9 patients in Phase II who needed 4AT screening. None of the patients who identified TPP correctly developed delirium during the entire hospitalization. There was no difference between patients who need 4AT screening in Phase 0 \& Phase II with $\mathrm{X}^{2}(1)=0.54, \mathrm{p}=0.46$. Only 4 out of the 9 patients, who underwent 4AT screening and had delirium bundle, achieved more $80 \%$ or more documentation rate.

\section{Secondary Outcomes}

\section{Incidence of Delirium}

There were 4 (8\%) patients diagnosed with delirium in Phase 0 and $3(6 \%)$ patients diagnosed with delirium in Phase II. There was no significant statistical difference in the diagnosis of delirium between two patient groups $\mathrm{X}^{2}(1)=0.28, \mathrm{p}=0.87$.

\section{Fall and Restraint Use}

There were no falls in Phase 0 . However, there was one patient who fell in toilet while showering in Phase II. This patient had no prior history of fall, low delirium risk, and three background comorbidities. There was no significant statistical difference in restraint use between two patient groups $\mathrm{X}^{2}(1)=4, \mathrm{p}=0.41$.

\section{LOS}

Patients with delirium had a longer LOS with difference of 6.77 days $(M=12.75, S D=4.65)$ than those without delirium $(M=5.98, S D=5.38)$ in Phase $0, t(48)=2.43, p=0.02$. However, different result was generated in LOS comparison for patient with and without delirium in Phase II. Despite the difference of 6.29 days in mean LOS between patients with delirium $(\mathrm{M}=13.67, \mathrm{SD}=2.31)$ vs without delirium $(\mathrm{M}=7.38, \mathrm{SD}=7.50)$, the statistical analysis did not 
Use of a Tailored, Multifaceted Educational Approach for Prevention and Early Detection of Delirium in Hospitalized Elderly Patients

show any significance $t(48)=1.43, p=0.16$. There was no statistical significance in LOS for patients with delirium between Phase $0(\mathrm{M}=12.75, \mathrm{SD}=4.65)$ \& Phase II $(\mathrm{M}=13.67, \mathrm{SD}=2.31), \mathrm{t}=-0.31, \mathrm{p}=0.77$.

\section{DISCUSSION}

This is the first prospective project studying the impact of a multifaceted educational approach combining theory and practice, which empowered nurses to apply their acquired knowledge to screen at-risk patients for delirium and initiate early prevention strategies in mixed medical/surgical units. It adopted a simple method to enable better knowledge synthesis and application in clinical practice by nurses. Not only were nurses' knowledge of delirium evaluated using a set of delirium case vignette, a measure of patient outcomes that would reflect the effectiveness of the training program on patient care was also afforded. Prior similar studies or projects were conducted mainly using Confusion Assessment Method (CAM) or other delirium screening tool ${ }^{[19-24]}$. The 4AT has not been widely utilized internationally until recent years with its easy use, time saving administration, and high sensitivity and specificity ${ }^{[28-31]}$. This project added value on further enhancing the use of 4AT delirium screening tool to benefit more patients.

The nurses' knowledge of delirium was grossly inadequate before the training with $60.7 \%$ of them having never attended any delirium related talk despite the fact that $95.1 \%$ of them had nursed a patient with delirium before. The nurses were not aware of the education material on delirium available online in the hospital for them to refer to either. Since Singapore is rapidly ageing, there will be more seniors occupying the inpatient beds in the hospitals, and delirium has been documented to be frequently overlooked by the local physicians (Chin, Koh, Tay, Tan, \& Merchant, 2016). Nurses are at a better position to recognize an early change in mental status or behavior since the frequency of contact between nurses and patients is longer compared to the physicians'. It is therefore more worthwhile to educate the nurses hospital wide to improve awareness of delirium in order to facilitate early screening, work up for causes and management of delirium as soon as the suspicion is raised (Lim, Chiam, Goh, Zhang, Png, \& Li, 2019).

There was a significant increase in nurses' knowledge of delirium at 1 week post training that was sustained after 1 month post training. Small group face-to-face training with simple information in combination with case discussions and ongoing bedside support (van den Boogaard, et al. 2009) by delirium ward champions could have played a very important part in sustaining the knowledge. E-learning tool for delirium alone may not be a good option in increasing knowledge or improving patient outcome (Detroyer, et al. 2018). The feedback obtained from nurses post training were favourable for the face to face encounter, and most of them preferred a real time interactive lecture and discussion compared to the passive online learning method. The active participation during case discussions improved understanding and retention of knowledge since the cases presented for teaching were common clinical vignettes which were familiar to the nurses during their day to day work. However, given the current pandemic situation where there were strict rules imposed by the Government to observe safe distancing, a compromise has to be struck. The teaching sessions took place with small groups of five nurses per session. It was tiring for the trainers to have to repeat the training 18 times in order to train all the nurses in the two wards. However, the small group teaching provoked more active participation and discussion. In order to sustain the education effort, there were identified ward champions to provide ongoing support as well as supplemental post E-learning on the hospital's intranet. The e resources will help to keep the nurses up to date with recent development on delirium.

Using TPP to assess patients' mental status for confusion is fast and effective in filtering patients at risk of delirium and to avoid routine implementation of 4AT to screen all elderly on a three times per day basis as this may give rise to fatigue and over diagnosis. Although the modified 4AT can be administered in less than 3 minutes per patient, it will substantially increase nurses' workload. Routine screening with the modified 4AT was also not recommended in the author's project since an abnormal score may be due to underlying chronic cognitive disorder like dementia. The nurses have not been formally educated on dementia and neither were they confident to distinguish between delirium and dementia. The next step of the education initiatives would be to teach the nurses on basics of dementia, behavioural symptoms and the differences between dementia and delirium. 
Use of a Tailored, Multifaceted Educational Approach for Prevention and Early Detection of Delirium in Hospitalized Elderly Patients

Another strength of this study was the implementation of the delirium care bundle. All the 9 patients who failed in identifying TPP correctly in Phase II were all initiated DCB. It served two purpose in this study. DCB was implemented to patients once they failed identify any one of the components in TPP regardless it was due to delirium, dementia or depression. DCB served as a prophylaxes in delirium prevention. For patients who were diagnosed delirium, DCB was served as an intervention measure to reduce complications of delirium.

The incidence of delirium was low in this project which could have been contributed by the small number of patients recruited. A significant number of patients requested for their family members to provide consent while some were unable to give consent due to their mental status. It is the typical Asian culture of children dominance, and leaving important decisions to family members (Tsai, 2010), which at times, can be frustrating and may well go against the patient's autonomy in certain situations. In this study, some of the family members were either unwilling to provide consent or had no time to come to the hospital to sign consent due to the current pandemic. There was no e-consent available for this project and the new research regulations in the author's institution require written consent from patient or family members further impeded the recruitment rate. The short duration of this study had also impacted on the recruitment rate.

Out of the total of 21 patients who needed 4AT screen, none of them had a fall. For the only patient who fell in Phase II, delirium was not attributed as the cause. Low fall rate could also be explained by the widespread use of restraints and extra precaution taken by nurses in nursing patients with delirium. Usage of physical restraints is rampant in the Asian culture to reduce risk of falls and injuries among the elderly who are unable to understand instructions (Chien \& Lee, 2007; Eskandari, Abdullah, Zainal, \& Wong, 2017). The current challenge of having to reduce or remove restraint use requires a change in culture and mind set as this was the traditional teaching passed down from the previous generations of nurses. The use of restraints was also contributed by the lack of understanding among the nurses on the needs of a person with dementia, especially the social and emotional needs. In the busy acute wards, the nurses prioritize their time attending to the patients' physical needs and tend to neglect the patients' other needs until a looming crisis consisting of screaming and physical aggression (Lim, Leng, Li, \& Zhang, 2019). All the nurses were taught to nurse patients with hyperactive or mixed type delirium near the nursing counter for better supervision.

The results also showed that patients with delirium stayed longer than patients without delirium which was in line with other studies (Geriatric Medicine Research Collaborative, 2019; McCusker, Cole, Dendukuri, \& Belzile, 2003; Stevens, de Moore, \& Simpson, 1998). However, there was no difference in LOS between patients who were diagnosed with delirium in Phase 0 and Phase II. This could have been impacted by the small sample size. The difference of 6.29 days in mean LOS for patients with delirium vs without delirium in Phase II did not achieve a statistical significance as the SD value of 7.50 was bigger than the mean of 7.38. This could have been impacted by the small sample size too. Prolonged length of stay is associated with poor patient outcome like nosocomial infections, cost and functional decline (Lim, Doshi, Castasus, Lim, \& Mamun, 2006). Therefore, a more robust study such as clustered randomized control study may produce better results.

\section{ConClusion}

This pilot study demonstrated significant improvement of nurses' knowledge in delirium. Though there were no significant differences in patients' outcome, such as fall, restraint use, and length of stay, the benefits of a training program which equips nurses with basic knowledge in delirium prevention \& early screening cannot be undermined. Long term knowledge sustainability is to be investigated at 6 month and 1-year interval.

\section{Acknowledgements}

The authors would like to thank Duke University, School of Nursing (SON) faculty; Singapore General Hospital, Nursing Division; Department of Internal Medicine; Department of General Surgery; and the staff of the participating wards. We also thank all consenting patients and their next of kin for their cooperation and participation. Special thanks are to the two ward champions and their ward nurse 
Use of a Tailored, Multifaceted Educational Approach for Prevention and Early Detection of Delirium in Hospitalized Elderly Patients

managers for the great support in making this project a wonderful experience for the study team.

\section{Abbreviations}

ANOVA: analysis of variance

CAM: Confusion Assessment Method;

CIRB: Centralised Institutional Review Board;

COVID-19: Coronavirus disease 2019

CPOE: Computerised Physician Order Entry;

CVHOA: Case Vignettes of Hospitalized Older Adults;

DCB: Delirium Care Bundle;

DNP: Doctor of Nursing Practice;

DWG: Delirium Workgroup;

ED: Emergency Department;

GS: General Surgery;

HELP: Hospital Elderly Life Program;

IM: Internal Medicine;

LOS: Length of Stay;

NICE: National Institute for Health and Care Excellence;

SON: School of Nursing;

SPSS: Statistical Package for the Social Sciences;

TPP: Time, Person and Place.

\section{Authors' Contributions}

ZRF, LSC, TSB, ESM contributed to the concept and design of the project. LSC, TSB, ESM supervised the project. ZRF, FWC, LJHM contributed to the acquisition of data. ZRF, LSC, ESM contributed to the analysis and interpretation of data. ZRF, LSC, TSB, ESM, VS, YKF contributed to drafting the article or revising it critically for important intellectual content. All authors have read and approved the final draft of the paper.

\section{Ethical Approval and Consent to Participate}

The project was approved by the Centralised Institutional Review Board, SingHealth, Singapore. Written informed consent was obtained from each patient or next of kin before inclusion. For nurses, returning of a set of completed questionnaire was considered as informed consent.

\section{REFERENCES}

[1] Department of Statistics Singapore. September 2020, Population trends. https://www.singstat. gov.sg/publications/population/populationtrends

[2] Ministry of Health. February 2017. Hospital admissions by sector, gender and age group. https://data.gov.sg/dataset/hospitaladmission-rate-by-age-and-sex

[3] Babine RL, Hyrkäs KE, Hallen S, et al. Falls and delirium in an acute care setting: A retrospective chart review before and after an organisationwide interprofessional education. J Clin Nurs. 2018;27(7-8):e1429-e1441.doi:10.1111/ jocn.14259

[4] Heeren P., Detroyer E., Milisen K. (2020) Delirium, Restraint Use and Falls. In: MonteroOdasso M., Camicioli R. (eds) Falls and Cognition in Older Persons. Springer, Cham. https://doi. org/10.1007/978-3-030-24233-6_13

[5] Kiely DK, Marcantonio ER, Inouye SK, et al. Persistent delirium predicts greater mortality. $J$ Am Geriatr Soc. 2009;57(1):55-61. doi:10.1111/ j.1532-5415.2008.02092.x

[6] Moskowitz EE, Overbey DM, Jones TS, et al. Postoperative delirium is associated with increased 5-year mortality. Am J Surg. 2017;214(6):10361038. doi:10.1016/j.amjsurg.2017.08.034

[7] Robinson TN, Raeburn CD, Tran ZV, Angles EM, Brenner LA, Moss M. Postoperative delirium in the elderly: risk factors and outcomes. Ann Surg. 2009;249(1):173-178. doi:10.1097/ SLA.0b013e31818e4776

[8] Bruce AJ, Ritchie CW, Blizard R, Lai R, Raven P. The incidence of delirium associated with orthopedic surgery: a meta-analytic review. Int Psychogeriatr. 2007;19(2):197-214. doi:10.1017/S104161020600425X

[9] Kotfis K, Szylińska A, Listewnik M, et al. Early delirium after cardiac surgery: an analysis of incidence and risk factors in elderly ( $\geq 65$ years) and very elderly ( $\geq 80$ years) patients. Clin Interv Aging. 2018;13:1061-1070. Published 2018 May 30. doi:10.2147/CIA.S166909 
Use of a Tailored, Multifaceted Educational Approach for Prevention and Early Detection of Delirium in Hospitalized Elderly Patients

[10] Yonekura H, Hirate H, Sobue K. Incidence, Risk Factors, and Effects on Outcome of Postoperative Delirium in Patients Undergoing Esophagectomy. Masui: The Japanese journal of anesthesiology. 2015;64(6):597-602.

[11] Chin YC, Koh GC, Tay YK, Tan CH, Merchant RA. Underdiagnosis of delirium on admission and prediction of patients who will develop delirium during their inpatient stay: a pilot study. Singapore Med J. 2016;57(1):18-21. doi:10.11622/smedj.2016007

[12] Edlund A, Lundström M, Karlsson S, Brännström B, Bucht G, Gustafson Y. Delirium in Older Patients Admitted to General Internal Medicine. Journal of Geriatric Psychiatry and Neurology. 2006;19(2):83-90. doi:10.1177/0891988706286509

[13] Elie M, Rousseau F, Cole M, Primeau F, McCusker J, Bellavance F. Prevalence and detection of delirium in elderly emergency department patients. CMAJ. 2000;163(8):977-981.

[14] Delirium: prevention, diagnosis and management. London: National Institute for Health and Care Excellence (UK); March 2019.

[15] American Geriatrics Society Expert Panel on Postoperative Delirium in Older Adults. American Geriatrics Society abstracted clinical practice guideline for postoperative delirium in older adults. J Am Geriatr Soc. 2015;63(1):142-150. doi:10.1111/jgs.13281

[16] RNAO, Screening for Delirium, Dementia and Depression in Older Adults. Registered Nurses' Association of Ontario (Toronto), (2 ${ }^{\text {nd }}$ ed.) BPG; 2016.

[17] RNAO, Delirium, Dementia, and Depression in Older Adults: Assessment and Care, Registered Nurses' Association of Ontario (Toronto), $\left(2^{\text {nd }}\right.$ ed.) BPG; 2016.

[18] Hshieh TT, Yue J, Oh E, et al. Effectiveness of Multicomponent Nonpharmacological Delirium Interventions: A Meta-analysis. JAMA Intern Med. 2015;175(4):512-520. doi:10.1001/ jamainternmed.2014.7779

[19] Siddiqi N, Harrison JK, Clegg A, et al. Interventions for preventing delirium in hospitalised non-
ICU patients. Cochrane Database Syst Rev. 2016;3:CD005563. Published 2016 Mar 11. doi:10.1002/14651858.CD005563.pub3

[20] Chen CC, Li HC, Liang JT, et al. Effect of a Modified Hospital Elder Life Program on Delirium and Length of Hospital Stay in Patients Undergoing Abdominal Surgery: A Cluster Randomized Clinical Trial. JAMA Surg. 2017;152(9):827-834. doi:10.1001/jamasurg.2017.1083

[21] Lundström M, Olofsson B, Stenvall $M$, et al. Postoperative delirium in old patients with femoral neck fracture: a randomized intervention study. Aging Clin Exp Res. 2007;19(3):178-186. doi:10.1007/BF03324687

[22] Travers C, Henderson A, Graham F, Beattie E. CogChamps: impact of a project to educate nurses about delirium and improve the quality of care for hospitalized patients with cognitive impairment. BMC Health Services Research. 2018; 18(1):534. https://doi.org/10.1186/s12913018-3286-4

[23] Kratz T, Heinrich M, Schlauß E, Diefenbacher A. Preventing postoperative delirium. Dtsch Arztebl Int. 2015;112(17):289-296. doi:10.3238/ arztebl.2015.0289

[24] Wong Tin Niam DM, Bruce JJ, Bruce DG. Quality project to prevent delirium after hip fracture. Australasian Journal on Ageing. 2005; 24:174-177. https://doi.org/10.1111/j.17416612.2005.00108.x

[25] Abraha I, Trotta F, Rimland JM, et al. Efficacy of Non-Pharmacological Interventions to Prevent and Treat Delirium in Older Patients: A Systematic Overview. The SENATOR project ONTOP Series. PLoS One. 2015;10(6):e0123090. Published 2015 Jun 10. doi:10.1371/journal. pone.0123090

[26] Hshieh TT, Yang T, Gartaganis SL, Yue J, Inouye SK. Hospital Elder Life Program: Systematic Review and Meta-analysis of Effectiveness. The American Journal of Geriatric Psychiatry. 2018;26(10):1015-1033. Published 2018 Jun 26. doi: 10.1016/j.jagp.2018.06.007.

[27] Milisen K, Foreman MD, Abraham IL, De Geest S, Godderis J, Vandermeulen E, ... Broos PLO. 
Use of a Tailored, Multifaceted Educational Approach for Prevention and Early Detection of Delirium in Hospitalized Elderly Patients

A Nurse-Led Interdisciplinary Intervention Program for Delirium in Elderly Hip-Fracture Patients.Journalofthe American Geriatrics Society. 2001;49:523-532. https://doi.org/10.1046/ j.1532-5415.2001.49109.x

[28] Bellelli G, Morandi A, Davis DHJ, Mazzola P, Turco R, Gentile S, ... MacLullich AMJ. Validation of the 4AT, a new instrument for rapid delirium screening: a study in 234 hospitalised older people. Age and Ageing. 2014;43(4):496-502. https://doi.org/10.1093/ageing/afu021

[29] Shenkin SD, Fox C, Godfrey M, et al. Delirium detection in older acute medical inpatients: a multicentre prospective comparative diagnostic test accuracy study of the 4AT and the confusion assessment method. BMC Med. 2019;17(1):138. Published 2019 Jul 24. doi:10.1186/s12916019-1367-9

[30] Jeong E, Park J, Lee J. Diagnostic Test Accuracy of the 4AT for Delirium Detection: A Systematic Review and Meta-Analysis. Int Environ Res Public Health. 2020;17(20):7515. Published 2020 Oct 15. doi:10.3390/ijerph17207515

[31] Tieges Z, Maclullich AMJ, Anand A, et al. Diagnostic accuracy of the 4AT for delirium detection in older adults: systematic review and metaanalysis [published online ahead of print, 2020 Nov 11]. Age Ageing. 2020;afaa224. doi:10.1093/ ageing/afaa224

[32] van den Boogaard, M., Pickkers, P., van der Hoeven, H., Roodbol, G., van Achterberg, T., \& Schoonhoven, L. (2009). Implementation of a delirium assessment tool in the ICU can influence haloperidol use. Critical care (London, England), 13(4), R131. https://doi.org/10.1186/ cc7991

[33] Detroyer, E., Dobbels, F., Teodorczuk, A., Deschodt, M., Depaifve, Y., Joosten, E., \& Milisen, K. (2018). Effect of an interactive E-learning tool for delirium on patient and nursing outcomes in a geriatric hospital setting: findings of a beforeafter study. BMC geriatrics, 18(1), 19. https://doi. org/10.1186/s12877-018-0715-5

[34] Tsai, D.F. (2010). Reflecting on the nature of Confucian ethics. Am J Bioeth.10(4),84-86. doi: $10.1080 / 15265161003686498$
[35] Stevens, L.E., de Moore, G.M., Simpson, J.M. (1998). Delirium in Hospital: Does it Increase Length of Stay? Australian \& New Zealand Journal of Psychiatry. 32(6),805-808. doi:10.3109/00048679809073869

[36] McCusker, J., Cole, M.G., Dendukuri, N., \& Belzile, E. (2003). Does delirium increase hospital stay?.J Am Geriatr Soc. 51(11),1539-1546. doi:10.1046/ j.1532-5415.2003.51509.x

[37] GeriatricMedicineResearchCollaborative (2019). Delirium is prevalent in older hospital inpatients and associated with adverse outcomes: results of a prospective multi-centre study on World Delirium Awareness Day. BMC medicine, 17(1), 229. https://doi.org/10.1186/s12916-0191458-7

[38] Lim, S.C., Chiam, W.M,, Goh, C.H., Zhang, D., Png, G.K., \& Li, F.Y. (2019). Initiatives to Improve Awareness of Delirium in a Teaching Hospital in Singapore: for Better Patient Care. Arch Neurol \& Neurosci, 2(3). http://doi.10.33552/ ANN.2019.02.000536

[39] Li, F., Lim, S.C. \& Png, G.K. (2020). Unpublished raw data on the accuracy of modified 4AT in delirium detection in acute hospital settings. Changi General Hospital (Unpublished results)

[40] Eskandari, F., Abdullah, K. L., Zainal, N. Z., \& Wong, L. P. (2017). Use of physical restraint: Nurses' knowledge, attitude, intention and practice and influencing factors. Journal of clinical nursing, 26(23-24), 4479-4488. https:// doi.org/10.1111/jocn.13778

[41] Chien, W.T., \& Lee, I.T.M. (2007). Psychiatric nurses' knowledge and attitudes toward the use of physical restraint on older patients in psychiatric wards. International Journal of Multiple Research Approaches. 1(1),5271, doi: 10.5172/mra.455.1.1.52

[42] Lim, S.C., Leng, T.H., Li, F.Y., \& Zhang, D. (2019). Nurses' attitude towards usage of physical restraints in a teaching hospital in Singapore. Open journal of Geriatrics. 2(1),29-35. Retrieved from http://www.sryahwapublications.com/ open-journal-of-geriatrics/pdf/v2-i1/6.pdf 
Use of a Tailored, Multifaceted Educational Approach for Prevention and Early Detection of Delirium in Hospitalized Elderly Patients

[43] Lim, S. C., Doshi, V., Castasus, B., Lim, J. K., \& Mamun, K. (2006). Factors causing delay in discharge of elderly patients in an acute care hospital. Annals of the Academy of Medicine, Singapore, 35(1), 27-32.

[44] Lim SC, Chiam WM, Goh CH, Zhang D, Png GK, Li FY. Initiatives to Improve Awareness of Delirium in a Teaching Hospital in Singapore: for Better Patient Care. Arch Neurol \& Neurosci. 2(3): 2019. ANN.MS.ID.000536.

[45] Fick, D.M., Hodo, D.H., Lawrence, F., \& Inouye, S.K. (2007). Recognizing delirium superimposed on dementia: assessing nurses' knowledge using case vignettes. J Gerontol Nurs. 33(2):40-7.

Citation: Rong Fang Zhang, Si Ching Lim, et al. Use of a Tailored, Multifaceted Educational Approach for Prevention and Early Detection of Delirium in Hospitalized Elderly Patients. Open Journal of Geriatrics. 2020; 3(2): 35-47.

Copyright: (c) 2020 Rong Fang Zhang, Si Ching Lim, et al. This is an open access article distributed under the Creative Commons Attribution License, which permits unrestricted use, distribution, and reproduction in any medium, provided the original work is properly cited. 